\title{
Water stress and abscisic acid exogenous supply produce differential enhancements in the concentration of selected phenolic compounds in Cabernet Sauvignon
}

\author{
Andrea Mariela Quiroga ${ }^{\mathrm{a}, 1}$, Leonor Deis ${ }^{\mathrm{b}, 1}$, Juan Bruno Cavagnaro ${ }^{\mathrm{b}}$, \\ Rubén Bottini ${ }^{\mathrm{b}}$ and María Fernanda Silva ${ }^{\mathrm{b}, *}$ \\ ${ }^{a}$ Facultad de Ingieniería y Ciencias Económico Sociales, Universidad Nacional de San Luis, Consejo Nacional de \\ Investigaciones Científicas y Tecnológicas (CONICET), Campus Universitario, Villa Mercedes, San Luis, Argentina \\ ${ }^{\mathrm{b}}$ Instituto de Biología Agrícola de Mendoza (IBAM), Facultad de Ciencias Agrarias - Universidad Nacional de \\ Cuyo - CONICET, Chacras de Coria, Luján de Cuyo, Mendoza, Argentina
}

Received 29 July 2011; accepted 23 August 2011

\begin{abstract}
The production of grapevine secondary metabolites can be magnified by abiotic stresses or exogenous abscisic acid. Selected phenolic compounds were determined in grape and wine by gas chromatography/mass spectrometry with the aim to asses the physiological responses of plants submitted to water stress and hormonal treatments. Exogenous abscisic acids as well as postveraison water stress produce differential enhancements on phenolic accumulation on Cabernet Sauvignon grapes and such effects were reflected in wine. Resveratrol and malvidin were enhanced by both abscisic acid and water stress and the improvement produced by such factors was additive. On the other hand, the synthesis of gallic acid, (+) catechin, quercetin and caffeic acid was not stimulated by water deficit. Combined hormonal-water stress treatments produced three positive effects on wine quality; a) increments of blue compounds, b) increments of flavonols and flavan 3-oles that favor copigmentation of wines, c) higher antioxidant compounds concentration with the consequent health benefits.
\end{abstract}

Keywords: Phenolic compounds, Cabernet Sauvignon, gas chromatography-mass spectrometry, abscisic acid, water stress

\section{Introduction}

Wine is considered a valuable source of nutraceuticals in which nature, art and science are involved [1]. The scientific community has found wine to be a very worthy subject for investigation. It has been demonstrated that the observed relationship between wine intake and health benefits is attributable to the red wine polyphenolic fraction $[2,3]$. Biological properties of functional foods and beverages rich in polyphenols are widely diversified, residing in the antioxidant, antihypertensive, cardioprotective, antiinflamatory, bactericide, antimutagenic, and antitumoral

\footnotetext{
${ }^{1}$ These authors contributed equally.

*Corresponding author: María Fernanda Silva, Instituto de Biología Agrícola de Mendoza (IBAM), Facultad de Ciencias Agrarias - Universidad Nacional de Cuyo - CONICET, Chacras de Coria, Luján de Cuyo, Mendoza, Argentina. Fax: +54 261 4135000; Ext: 1307; E-mail: msilva@ fca.uncu.edu.ar.
} 
activities of these pharmaconutrients $[4,5]$. Among them, red grapes and wines are particularly rich in bioavailable phenols that are rapidly absorbed as intact molecules and delivered into the brain within minutes from their ingestion [6]. The composition and concentration of phenols in grapes and wines are influenced by different factors including grape variety, edaphoclimatic conditions, and cultural and technological practices [6].

The production of grapevine secondary metabolites can be magnified by abiotic stresses such as drought as well as extremes of light exposure and temperature [7-9].

Stress is described as every external factor that has a negative influence on plants related to their survival, yield and vegetative production [10]. Although water stress is one of the most limiting factors in cultivated areas, it has been demonstrated in grape that a moderate water restriction is useful to improve organoleptic quality of wine [11].

In plants, a physiological response to water stress is the biosynthesis stimulation of abscisic acid (ABA). ABA is the hormonal sign that transports the message of stress sensed in roots producing diverse physiological responses [12]. The latter has already been demonstrated for several extensive crops including grape [13]. Furthermore, it has been reported that in-field treatments with exogenous ABA supplies produce the closure of stomata thus contributing to water economy as well as improving biomass production $[14,15]$. On the other hand, it has been demonstrated that phenolic accumulation is enhanced by ABA [8, 16-18]. Ban et al. [16] reported that the anthocyanin levels resulting from the applications of ABA were correlated with the expression of anthocyanin biosynthetic pathway genes.

In contrast to this important effect on grape quality, external ABA supply in grape berries has not yet been used as a regular agronomic practice due to its high cost for an extensive crop. For that reason, it is important to determine the opportune moment of application of $\mathrm{ABA}$ and, moreover, design a strategy to combine it with the benefits of water stress.

Anthocyanin biosynthesis in grape skin has been extensively studied; it has been determined that anthocyanins are synthesized from phenylalanine through an anthocyanin biosynthetic pathway regulated by enzyme activities [19] and gene expressions [20]. The most important anthocyanin biosynthetic pathway enzymes are: phenylalanine ammonia lyase (PAL), chalcone synthase (CHS), chalcone isomerase (CHI), flavonol synthase (FLS1), flavanone 3-hydroxylase $(\mathrm{F} 3 \mathrm{H})$, flavanone 3,5-hydroxylase $(\mathrm{F} 35 \mathrm{H})$, dihydroflavonol 4-reductase (DFR), leucoanthocyanidin dioxygenase (LDOX) and UDP-glucose: flavonoid 3-O-glucosyltransferase (UFGT), [20-23]. F3 H and F35 H are also involved in the biosynthetic pathway of flavonols (quercetin and myricetin), flavan-3-ols (e.g. catechin, epicatechin, and epigallocatechin of grapes) and dihydroxiled and trihydroxiled anthocyanins. Leucoanthocyanidin reductase (LAR) and anthocyanidins reductase (ANR) divert the pathway towards favan-3-oles. FLS1 is an enzyme that catalyzes the chemical reaction which produces flavonols [24].

Taking into account the health benefits and the impact on wine quality, a great deal of effort is being carried out in recent years for the development of accurate, sensitive, robust, versatile and cost effective analytical methodologies for the simultaneous determination of phenolic compounds in samples of enological interest. Thus, monitoring of phenolic compounds in wine and its precursors is of vital importance for quality and process control in the wine industry.

UV-Vis spectrophotometry after standard precipitation or solvent extraction procedures are the most used techniques for the determination of total phenol content in wine and grape $[3,25,26]$. Such analyses provide a rapid and appropriate response to the requirements of wine manufactures, but it cannot be used as a tool to identify and quantify individual phenolic compounds. Furthermore, since other compounds present in the matrix may contribute to the absorbance, these methods are characterized by poor selectivity. To date, a number of analytical methods are available for the simultaneous determination of grape and wine phenolics including those based on separation techniques such as Gas and Liquid Chromatography (GC, HPLC) and Capillary Electrophoresis (CE) [27-32]. Nevertheless, even the latest chromatography techniques still produce relatively limited results and in many cases structural analysis still remains unclear.

Liquid Chromatography (LC/MS) and Gas chromatography (GC/MS) coupled to mass spectrometry have greatly facilitated the identification and quantification of phenols in biological materials [33-36]. LC/MS is often preferred since, in contrast to GC/MS, does not require derivatization, and allows the simple development of speciation studies. However, the significant higher cost of HPLC/MS instruments is a limiting factor to many analytical labs. GC-MS has long been ideal for profiling metabolites due to its superior separation properties and the availability of library data bases. Nevertheless, extensive liquid-liquid or solid-phase (SPE) extraction methodologies followed by derivatization have usually been applied prior to the GC/MS analysis. 
The aim of the present study was to evaluate whether water stress and hormonal treatments applied at different stages have effect on the biosynthesis of some representative phenolic compounds. A combined ultrasonication extractionGC-MS method is proposed for the simultaneous determination of phenolic compounds in grape and wine. Our results demonstrated that ABA sprays as well as postveraison water restriction produces a differential enhancement on phenolic accumulation of Cabernet Sauvignon grapes and such effects were reflected in wine. Interestingly, as assessed by the evaluation of the combined in-field treatments, in some cases the improvements produced by such factors were additive.

\section{Materials and methods}

\subsection{Chemical and reagents}

Resveratrol, gallic acid, caffeic acid, (+)-catechin and gallic acid were purchased from Sigma Chemical co. (St. Louis, Mo); quercetin was purchased from Extrasynthese (Genary, France). Standards of cyanidin chloride and malvidin chloride were from Fluka (Sigma-Aldrich, Steinheim, Germany). The derivatizating reagent N,Obis(trimethylsilyl) trifluoroacetamide (BSTFA) was acquired from SUPELCO (Bellefonte, USA) and pyridine was purchased from Fluka (Sigma-Aldrich, Steinheim, Germany). All others reagents and solvents were of analytical grade quality.

\subsection{Plant material. Experimental field procedures}

The assays were performed on a 12 year-old Vitis vinifera L. cv. Cabernet Sauvignon vineyard at Finca San Antonio, Faculty of Agronomic Sciences, National University of Cuyo, Mendoza, Argentina, (920 m.a.s.1., 68 ${ }^{\circ} 53^{\prime} \mathrm{W}$, $\left.33^{\circ} 02^{\prime} \mathrm{S}\right)$. With the purpose to study the effects of exogenous hormonal supply and water stress on the accumulation of polyphenols on grape skin and wine, several in-field treatments were performed from bud burst to harvest during two seasons. Two principal treatments were established: water status and ABA. A $250 \mathrm{~mL}$ of a $250 \mathrm{mg} \mathrm{L}^{-1} \mathrm{ABA}^{-}$ solution aliquot was sprayed per plant (on clusters). The treatments were as follows: $\mathbf{C}$ (control treatment, predawn leaf water potential was kept within the interval: $0.00-0.30 \mathrm{MPa}$, not sprayed with ABA), A1 (first year hormonal treatment, supply between veraison to harvest weekly, four applications), A2, (second consecutive year hormonal treatment, weekly supply between veraison to harvest, four applications), Ae (first year hormonal treatment, ABA was supplied on a single date at flowering) and $\mathbf{S}$ (water stress, predawn leaf water potential was kept within the interval: - 0.30-0.70 MPa). Also, combined water stress-hormonal treatments were performed as follows: CC, control well watered vines without ABA; CA1, control well watered vines sprayed with ABA for the first year from veraison to harvest; CA2 control well watered vines sprayed with ABA for the second consecutive year from veraison to harvest; CAe, control well watered vines sprayed with ABA for the first year just once at flowering; SC, moderate water stressed without ABA; SA1, moderate water stressed vines sprayed with ABA for the first year from veraison to harvest; SA2, moderate water stressed vines sprayed with ABA for the second consecutive year from veraison to harvest. 6 replications were performed for each treatment.

\subsection{Sampling}

Berries were collected in nylon bags ( 10 berries from 5 clusters) at the moment of harvest, when sugar concentration reached $24^{\circ}$ Brix. Fifty grape berries from different cluster positions were considered as one replication. In the field, samples were kept in ice to prevent dehydration. At the laboratory, then were frozen and conserved at $-20^{\circ} \mathrm{C}$ until analysis.

\subsection{Microfermentations}

In order to obtain 6 replicates for each treatment, winemaking was carried out according to the following procedure. Harvest was done at the same date for all treatments, (March, 20 for the first year, March, 22 for the second year). 
The grapes from each plant were harvested separately, crushed and destemmed. Then, grapes from two plants were placed in a mini tank, and they were homogenized with the addition of $10 \mathrm{mgL}^{-1}$ potassium metabisulfite. The must was inoculated with $20 \mathrm{mgL}^{-1}$ of selected commercial Saccharomyces cervisiae bayanus yeast. During fermentation, musts were racked twice a day. Temperature and density were measured daily. When the alcoholic fermentation was completed, sulfur dioxide $\left(60 \mathrm{mgL}^{-1}\right)$ was added as potassium metabisulfite. During winemaking no clearing agents or pectolytic enzymes were used and temperature was maintained at $7^{\circ} \mathrm{C}$. Wine was racked periodically and bottled three months after its preparation.

\subsection{Ultrasonic-mediated extraction and derivatization procedures}

Ultrasonication was employed to assist and accelerate the extraction of the phenolic compounds from vegetal tissues and wine into the solvent phase. The skins of fifty frozen berries of each replication were manually and carefully removed with aid the a bistoury, cut into small pieces, mixed and bagged on aluminium foil. Wine samples were homegeneized prior sampling. The sample aliquots $(10 \mathrm{mg}$ of grape skin or $0.20 \mathrm{~mL}$ wine $)$ were placed in a $5 \mathrm{~mL}$ glass vial together with $4 \mathrm{mg}$ sodium chloride and $4 \mathrm{mg}$ potassium metabisulfite and subjected to three successive liquid extraction steps with $0.60 \mathrm{~mL}$ of acidified ethyl acetate mediated by ultrasonication $(200 \mathrm{~W})$ (Cleanson CS1106, Buenos Aires, Argentina) for 7 minutes. The supernatants were collected in a glass vial and filtered through a glass conic minicolumn packed with $\mathrm{Na}_{2} \mathrm{SO}_{4}$ in order to eliminate any water residue. Next, $1.50 \mathrm{~mL}$ of the solution was evaporated to dryness under a gentle stream of nitrogen. The solid residue was spiked with $70 \mu \mathrm{L}$ of BSTFA and $30 \mu \mathrm{L}$ of pyridine. After $40 \mathrm{~min}$ at $70^{\circ} \mathrm{C}$, an aliquot of the solution was analyzed by GC-MS. Each sample was injected three times.

\subsection{Chromatographic conditions. Qualitative and quantitative analysis by GC-MS}

Capillary GC-MS analyses were performed with a Clarus 500 gas chromatograph equipped with an autosampler and split/splitless injection port interfaced with a Clarus 500 quadrupole mass spectrometer from Perkin Elmer (Shelton, CT, USA). An Elite 5MS fused silica capillary column (Perkin Elmer, Shelton, CT, USA) was used; the dimensions of the column were $30 \mathrm{~m} \times 0.25 \mathrm{~mm}$ i.d., $0.25 \mu \mathrm{m}$ film thickness with a stationary phase of (5\%-Diphenyl)-dimethylpolysiloxane. Ultra high-purity helium with an in-line gas filter (Perkin Elmer, CT, USA) was used as a carrier gas. Helium flow rate and split ratio were adjusted to $1 \mathrm{~mL} \mathrm{~min}^{-1}$ and $35: 1$, respectively. The injection port, transfer line, and source were set at 300,280 and $260^{\circ} \mathrm{C}$, respectively. The oven temperature was controlled by the following program: initial temperature $80^{\circ} \mathrm{C}(1 \mathrm{~min}$ hold $)$, a ramp to $250^{\circ} \mathrm{C}$ at $20^{\circ} \mathrm{C}$ min $^{-1}$, then a ramp to $300^{\circ} \mathrm{C}$ at $6^{\circ} \mathrm{C} \mathrm{min}^{-1}(2 \mathrm{~min}$ hold $)$, then a ramp to $320^{\circ} \mathrm{C}$ at $20^{\circ} \mathrm{C} \mathrm{min}^{-1}(24 \mathrm{~min}$ hold $)$. The mass spectrometer was calibrated with heptacosafluorotributylamine (Fluka, Sigma-Aldrich, Steinheim, Germany) at an electron impact ionization energy of $70 \mathrm{eV}$. The acquisition mass range was $\mathrm{m} / \mathrm{z} 70-700$. Acquisition started 4 minutes after sample injection. The temperature of the injector was maintained at $300^{\circ} \mathrm{C}$, and the sample volume injected was $1 \mu \mathrm{L}$ in the splitless mode. The analytical performance of the GC-MS was verified daily before use.

Identification of each phenolic compound in each derivatized extract of wine and/or grape skin was set up by comparing their GC retention times and trimethylsilyl (TMS) derivative mass spectra to those of the derivatized standards. A target ion and at least two qualifying ions were chosen for each of the compounds on the basis of their abundance and specificity (Table 1). The concentrations of the identified phenolic compounds in each sample were calculated from the calibration plots. Standard solutions were subjected to the same extraction/derivatization procedure than samples. The calibration plots were obtained representing the areas vs concentrations.

\subsection{Statistics}

An analysis of variance (ANOVA) was utilized, with treatment and blocks as main factors, using a Statgraphics Plus 4.0 Software program. The Fisher's least significant difference (LSD) procedure was used for discriminating among the means of the variables $(p \leq 0.05)$. 
Table 1

GC retention times, target and qualifying ions for each trimethylsilyl (TMS) derivatized standard

\begin{tabular}{lcccc}
\hline Standards & TMS-Phe MW $^{\mathrm{a}}$ & $\mathrm{t}_{\mathrm{R}}(\mathrm{min})$ & Target ion $(\mathrm{m} / \mathrm{z})$ & Qualifier ions $(\mathrm{m} / \mathrm{z})$ \\
\hline gallic acid & 458 & 9.74 & 281 & 458,443 \\
malvidin & 619 & 21.2 & 619 & 589,295 \\
cyanidin & 574 & 19.27 & 574 & $645,556,392$ \\
(+)-catechin & 650 & 16.64 & 650 & $368,355,267$ \\
quercetin & 662 & 19.41 & 647 & $575,559,487$ \\
resveratrol & 444 & 15.17 & 429 & 444,147 \\
caffeic acid & 396 & 10.48 & 396 & 381,307 \\
cinnamic acid & 220 & 7.29 & $220 / 221$ & $220,205,161$ \\
\hline
\end{tabular}

Experimental conditions as described in sections 2.5 and 2.6 ; ${ }^{\text {a }}$ Molecular weight of the trimethylsilyl (TMS) derivatized standard.

\section{Results and discussion}

Definitely, the development, optimization and validation of the present methodology are compulsory to evaluate the physiological responses of plants of Vitis vinifera cv Cabernet Sauvignon submitted to water stress and hormonal treatments. The analytes were chosen based not only on their representativeness in wine but also for the significance of their enhancement after in field treatments. Understanding the analytical results is the set up of the accurate and objective evaluation of wine quality and the efficiency of plant treatments.

\subsection{Optimization of the extraction-derivatization parameters}

The effect of several experimental parameters upon extraction efficiency and reaction conditions concerning sensitivity, selectivity, reproducibility and robustness were thoroughly evaluated and optimized. A three-stage sequence of variations was applied by the one-at-a-time procedure. The first sequence involved the extraction conditions, the second the derivatization parameters while the third one the chromatographic/detection factors. The chromatographic peak was used to evaluate the extraction efficiency, derivatization product yields and separation/quantification efficacy under different experimental conditions.

\subsubsection{Selection of the extraction conditions}

The following parameters were consecutively optimized: extraction solvent nature and composition, sample and extracting solvent volumes, ultrasonication time and temperature and the number of successive extractions. Taking into account the chemical nature of the analytes under study, acidified methanol, acetone and ethyl acetate were examined in order to find the optimal extraction from grape skin. The best results were obtained with ethyl acetate acidified with $\mathrm{HCl}$ (final concentration $=0.01 \% \mathrm{v} / \mathrm{v}$ ). Different sample amounts (grape skin: 5-50 mg, wine: $50-500 \mu \mathrm{L}$ ) and extracting solvent volumes $(200-1000 \mu \mathrm{L})$ were tested. We concluded that the minimum number of successive extractions necessary to achieve quantitative phenolic extraction was three successive extractions mediated by a 7-minutes ultrasonication step. Temperature did not influence the extraction efficiency to any considerable extent within the interval $20-50^{\circ} \mathrm{C}$. Higher temperatures are not adequate due to the thermal instability of the analytes. The optimal analytical parameters were achieved for the following conditions: three successive liquid extraction steps with $600 \mu \mathrm{L}$ of acidified ethyl acetate mediated by ultrasonication $(200 \mathrm{~W})$ during 7 minutes at $25^{\circ} \mathrm{C}$ for $10 \mathrm{mg}$ of grape skin or $200 \mu \mathrm{L}$ of wine.

\subsubsection{Selection of the derivatization conditions}

Minimal solvent consumption and an alternative heating method, such as microwave-accelerated derivatization (MAD) were tested towards improving the derivatization process. Microwave radiation can greatly speed up the silylation of the analytes under study since it will promote the molecular dipole rotational energy level of the O-H 
bonds; the large dipole moment of phenolics turn such compounds to be ideal candidates for microwave-accelerated reactions.

In this study, parameters affecting MAD, including reaction time (10-120 s), BSTFA/pyridine ratio and solvent volume (50-200 $\mu \mathrm{L})$ were systematically optimized. For comparison with the results obtained by microwave accelerated method, silylation was performed in the classical mode during $40 \mathrm{~min}$ at $70^{\circ} \mathrm{C}$. In all cases, reaction yields were evaluated through analyte peak areas. Our data, taken after reaction times of 10, 20, 40, 60 and $120 \mathrm{~s}$ under $100 \%$ microwave irradiation power showed an increase in the extraction efficiency for the range 10-40 s, while reaction times higher than $40 \mathrm{~s}$ had no appreciable effect upon silylation efficiency. Concerning the derivatizing agent, above a reagent to pyridine ratio of $70: 30$, no variation took place in the sensitivity of the method. For the sample amounts tested ( $10 \mathrm{mg}$ berry skin or $0.20 \mathrm{~mL}$ wine) the optimal derivatizing agent volume was $0.1 \mathrm{~mL}$. MAD generated derivatization conditions comparable to traditional methods in shorter time periods and more reproducible results; the rapid (40 s) derivatization reactions associated with MAD had comparable yields with those obtained with thermal heating (40 min).

\subsection{Separation method development}

The optimization was performed using a synthetic mixture of resveratrol, gallic acid, caffeic acid, (+)-catechin, vanillin, trans-cinnamic acid, $p$-coumaric acid, gallic acid, ferulic acid, quercetin, cyanidin chloride and malvidin chloride. Figure 1 shows the chromatogram of a grape skin sample and the mass spectra of TMS-gallic acid and Fig. 2 a chromatogram of a wine sample extract. Table 1 shows the GC retention times, target and qualifying ions for each trimethylsilyl (TMS) derivatized standard. The following parameters were consecutively optimized: injection, interface and source temperatures, carrier gas pressure and oven program.
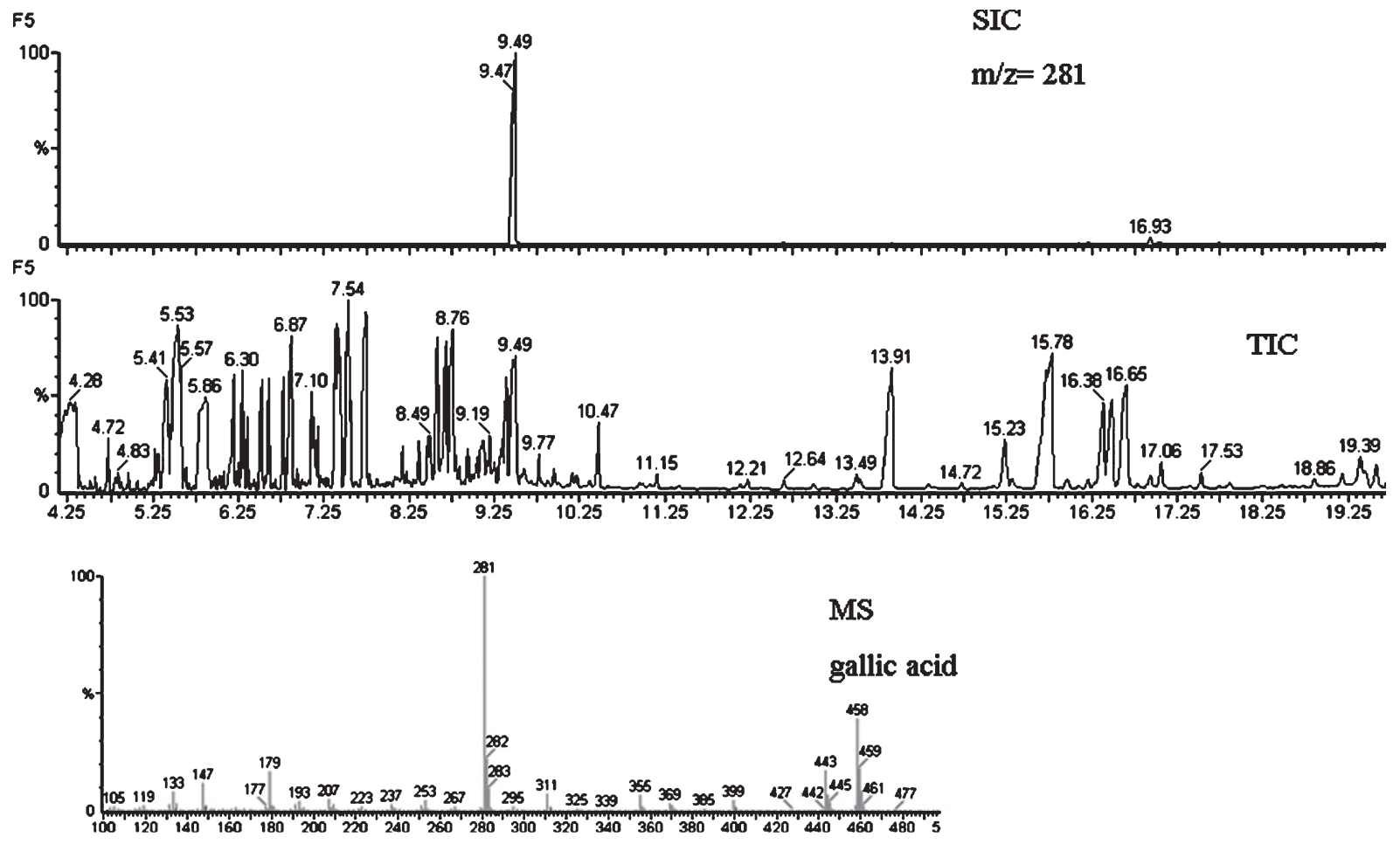

Fig. 1. Chromatogram of a grape skin sample and mass spectrum of TMS-gallic acid. Experimental conditions as described in Sections 2.5 and 2.6. MS: TMS-gallic acid mass spectrum; TIC: total ion chromatogram Cabernet Sauvignon grape skin sample; SIC: single ion chromatogram extracted from the TIC. 


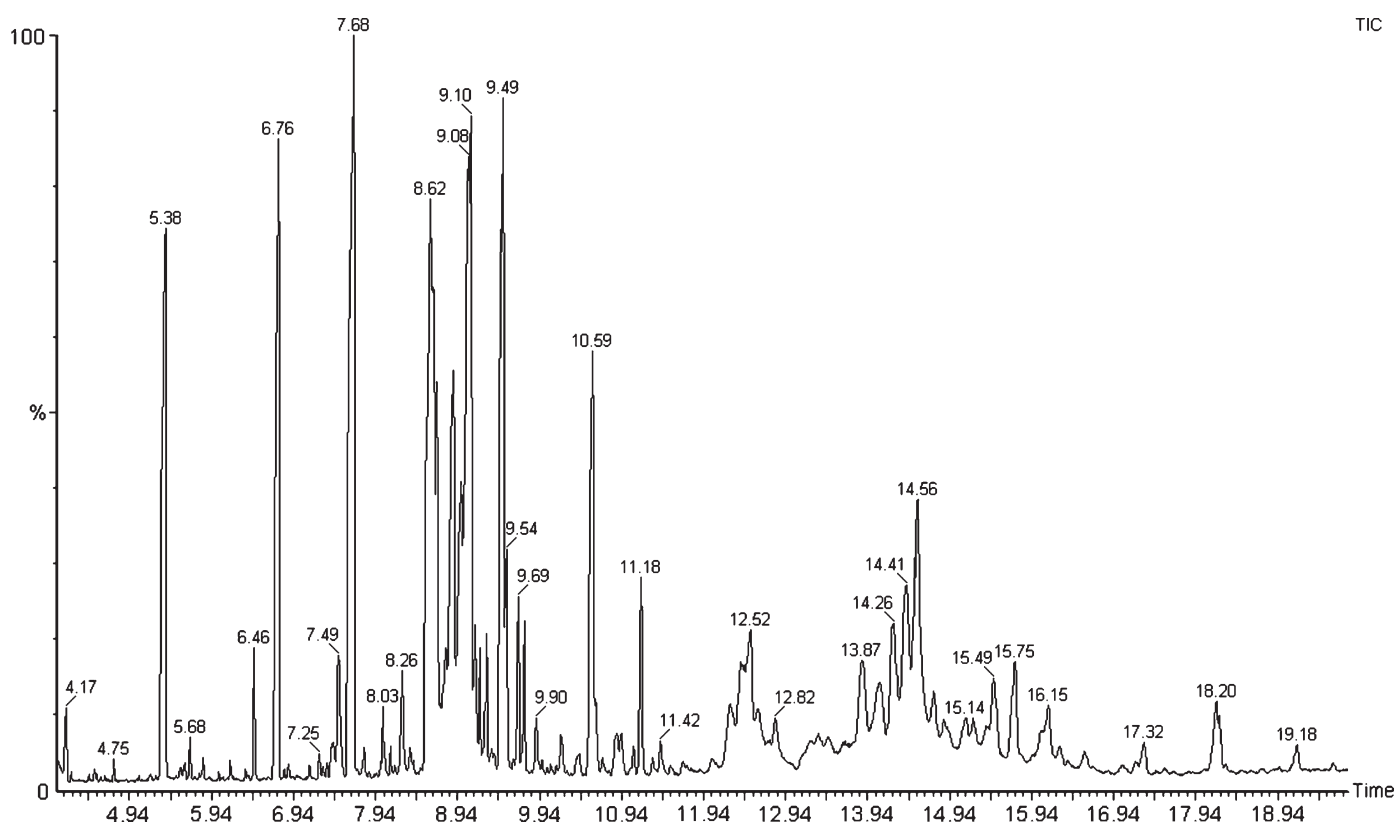

Fig. 2. Chromatogram of a wine extract sample. Experimental conditions as described in Sections 2.5 and 2.6. TIC: total ion chromatogram Cabernet Sauvignon wine sample.

Table 2

Analytical performance of the method

\begin{tabular}{lcccc}
\hline Analyte & RSD (\%)* & $\begin{array}{c}\text { Linear range* } \\
\left(\mathrm{mg} \mathrm{L}^{-1}\right)\end{array}$ & $r^{2 *}$ & $\begin{array}{c}\mathrm{LOD}^{*} \\
\left(\mathrm{mg} \mathrm{L}^{-1}\right)\end{array}$ \\
\hline gallic acid & 2.3 & $0.10-70.00$ & 0.9987 & 0.019 \\
malvidin & 3.4 & $1.38-50.00$ & 0.9994 & 0.410 \\
cyanidin & 5.6 & $0.61-50.00$ & 0.9986 & 0.162 \\
(+)-catechin & 5.2 & $0.12-40.00$ & 0.9989 & 0.024 \\
quercetin & 2.4 & $0.06-30.00$ & 0.9991 & 0.010 \\
resveratrol & 1.6 & $0.16-18.00$ & 0.9989 & 0.053 \\
caffeic acid & 4.1 & $0.04-30.00$ & 0.9988 & 0.012 \\
cinnamic acid & 3.8 & $0.04-10.00$ & 0.9992 & 0.014 \\
\hline
\end{tabular}

*95\% confidence interval; $n=6$; RSD: relative standard deviation; LOD: limit of detection; $r^{2}$ : correlation coefficient.

\subsection{Analytical performance}

The calibration plots were measured under the optimal experimental conditions from aqueous standard solutions containing $15 \%(\mathrm{v} / \mathrm{v})$ ethanol, $\mathrm{pH}: 3.50$. Six points of the calibration curve were determined, and three replicate injections of standards at each concentration level were performed. The calibration equations were calculated by the least-squares linear regression method, and unknown concentrations were calculated by interpolation. The detection (LOD) and quantification (LOQ) limits were calculated as the analyte concentrations that gave rise to peak heights with signal-to-noise ratios of 3 and 10, respectively. LOD and LOQ were determined by injecting standard combined solutions at three different concentrations for each analyte. Table 2 shows the concentration ranges for calibration curves of each analyte and limits of detection and quantitation. Standard solutions were subjected to the same extraction/derivatization procedure than samples. 
To determine the repeatability (within-day precision) of the method, replicate injections $(n=6)$ of a synthetic solution containing the analytes within the concentration range $0.50-40.00 \mathrm{mg} \mathrm{L}^{-1}$ were carried out. In all cases, the precision was better than $0.84-4.18 \%$ for the retention times and $2.88-7.64 \%$ for the peak areas. Good peak area precision was achieved without adding any internal standard.

An important aspect of the proposed methodology is the low organic solvent consumption, which turns it into a low cost and environmental friendly technique. The optimized approach has proven to be a robust, sensitive, cost effective and versatile method for simultaneously determining phenolic compounds in different samples of oenological interest during the whole winemaking and aging process.

\subsection{Recovery studies}

To determine the accuracy of this method, $2 \mathrm{~mL}$ of red wine was collected and divided into 10 portions of $200 \mu \mathrm{L}$ each. The proposed method was applied to six portions, and the average concentrations determined for each compound were taken as a base value. Then, known quantities of the analytes were added to the other aliquots, and the phenolic compounds were determined following the recommended procedure. Recoveries are expressed as follows:

$$
\% R=100 \times\left[\begin{array}{c}
\left(C_{f}-C_{b}\right) \\
C_{a}
\end{array}\right]
$$

Where $C_{f}$ represents the concentration found, $C_{b}$ the base value concentration and $C_{a}$ the added concentration. The recovery studies showed satisfactory robustness leading recoveries higher than $86.00 \%$ and lower than $112.00 \%$ for all the analytes under study.

\subsection{Analysis of samples}

Growing grapevines under water stress treatment has long been regarded as an agronomic tool for improving polyphenol content in berries [37, 38]. However, the accurate implementation of this practice is not simple and there are several disadvantages associated to this agronomic tool including growth restriction, lower photosynthetic rates and carbohydrate reserves, diminished yields (up to 50\%), and even a generalized damage of crops [11].

Abscisic acid is a phytohormone involved in stress responses, [8, 12, 18, 39, 40]. Keeping in mind that ABA is involved in the signaling chain of water stress in plants $[12,40]$ there is an emerging hypothesis that ABA application to the grape plant may allow growers to meet practical objectives with regard to fruit quality, and do so without the problems associated with water stress. Moreover, in a previous work [18] we have verified that ABA applications in flowering can significantly enhance yield per plant in field-grown grapes by favoring increase berry set without diminishing the quality of the fruits for winemaking use. Indeed, the response to stress and hormonal treatment upon the synthesis and stability of phenolic compounds is varietal and terroir-dependent [41].

Once the conditions for the extraction/reaction/separation conditions were established, the optimized procedure was performed on samples that had been submitted to season hormonal and water stress treatments as described in Sect. 2.2. Sampling and sample pretreatment were performed following the procedures shown in Sects. 2.3, 2.4 and 2.5. The results are shown in Fig. 3 (grape skin samples) and Table 3 (wine samples).

The results of our study clearly indicate that exogenous ABA supply produces enhancements on the accumulation of the phenolic compounds under study on grapes and those increments were reflected in wine. Nevertheless, differential responses were observed.

Responses to treatments were comparable for grape and wine. Water stress induced a lower gallic acid concentration respect to control. On the other hand, ABA supply increased its synthesis. SA treatments showed intermediate gallic acid concentrations; that could be ascribable to the fact that water stress decreased its biosynthesis while ABA induces its production. Similar effects were observed for caffeic acid.

Resveratrol was enhanced by water stress, while ABA supply increased its biosynthesis only for postverasion applications. Taking into account the largely proved beneficial effects of this phenolic compound for human health, the agronomical practices proposed in the present approach should be considered in order to increase the nutraceutical properties of red wine [1]. 

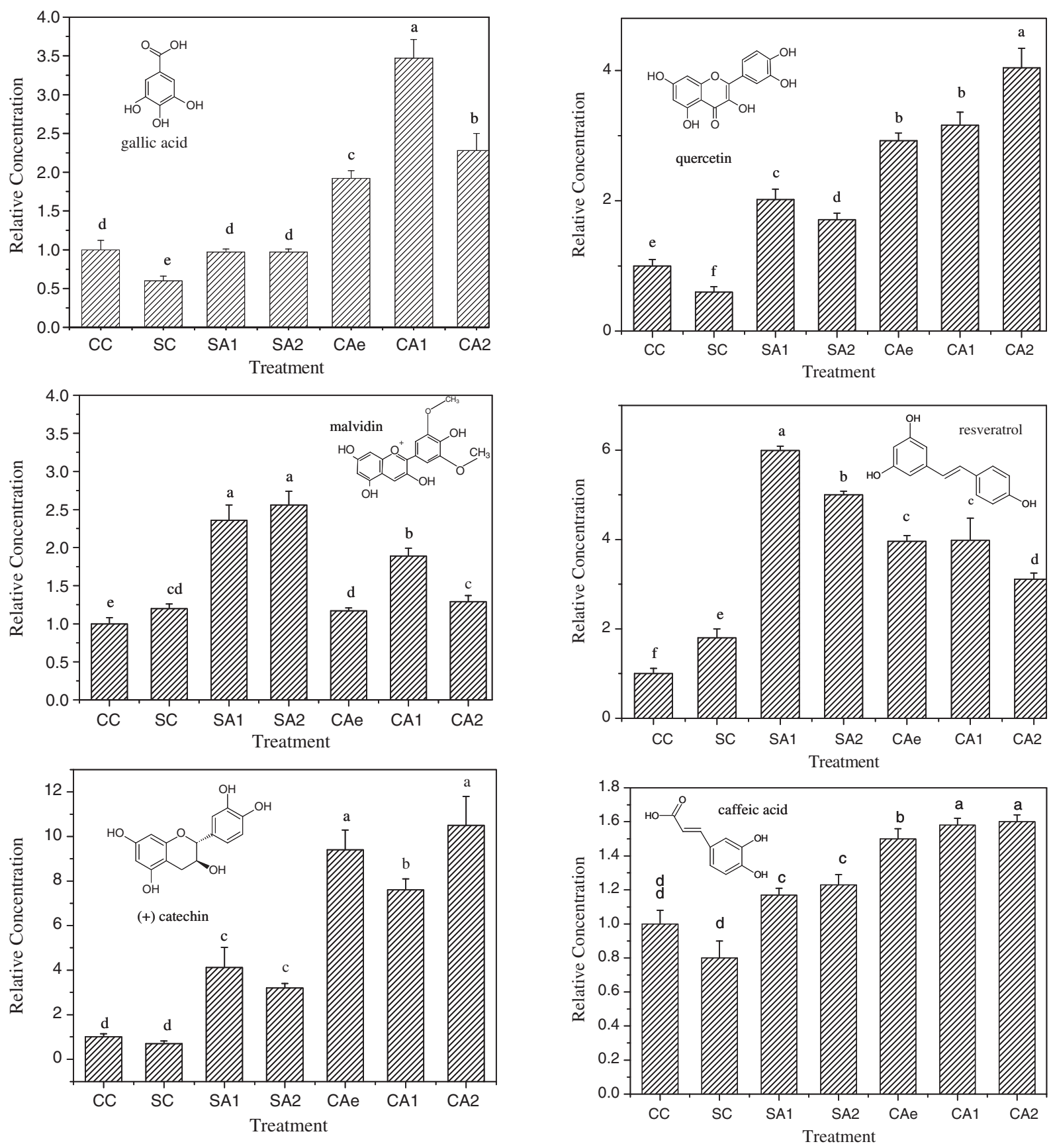

Fig. 3. Relative Polyphenol Concentration ${ }^{\mathrm{a}}$ in Cabernet Sauvignon grape skin at harvest after exogenous hormonal supply and water stress.

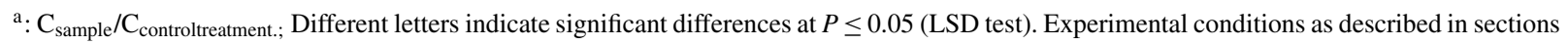
2.5 and $2.6, n=6$. CC: control treatment, water potential was kept within the interval: $0.00-0.30 \mathrm{MPa}$, SC: water stress, water potential was kept within the interval: $-0.30-0.70 \mathrm{MPa}, \mathrm{CA1}$ : abscisic acid first year treatment, CA2: abcsisic acid second year treatment, CAe: abscisic acid was supplied on a single date, SA1: combined treatment, water stress + abscisic acid first year treatment, SA2: combined treatment, water stress+abscisic acid second year treatment. 
Table 3

Polyphenol content in Cabernet Sauvignon wines after exogenous hormonal supply and water stress

\begin{tabular}{|c|c|c|c|c|c|c|c|c|}
\hline Treatment & $\begin{array}{c}\text { Gallic acid } \\
\left(\mathrm{mg} \mathrm{L}^{-1}\right)\end{array}$ & $\begin{array}{l}\text { Malvidin } \\
\left(\mathrm{mg} \mathrm{L}^{-1}\right)\end{array}$ & $\begin{array}{c}(+) \text { Catechin } \\
\left(\mathrm{mg} \mathrm{L}^{-1}\right)\end{array}$ & $\begin{array}{l}\text { Quercetin } \\
\left(\mathrm{mg} \mathrm{L}^{-1}\right)\end{array}$ & $\begin{array}{c}\text { Resveratrol } \\
\left(\mathrm{mg} \mathrm{L}^{-1}\right)\end{array}$ & $\begin{array}{c}\text { Caffeic acid } \\
\left(\mathrm{mg} \mathrm{L}^{-1}\right)\end{array}$ & $\begin{array}{c}\text { Cinnamic acid } \\
\left(\mathrm{mg} \mathrm{L}^{-1}\right)\end{array}$ & $\begin{array}{c}\text { Cyanidine } \\
\left(\mathrm{mg} \mathrm{L}^{-1}\right)\end{array}$ \\
\hline $\mathrm{CC}$ & $\begin{array}{c}13.00 \pm 1.80 \\
\text { (d) }\end{array}$ & $\begin{array}{c}3.40 \pm 0.22 \\
\text { (d) }\end{array}$ & $\begin{array}{c}0.81 \pm 0.09 \\
\text { (d) }\end{array}$ & $\begin{array}{c}0.12 \pm 0.02 \\
\text { (c) }\end{array}$ & $\begin{array}{c}1.65 \pm 0.12 \\
\text { (c) }\end{array}$ & $\begin{array}{c}10.00 \pm 0.90 \\
\text { (e) }\end{array}$ & $\mathrm{ND}^{*}$ & ND \\
\hline $\mathrm{SC}$ & $\begin{array}{c}6.00 \pm 0.80 \\
\text { (e) }\end{array}$ & $\begin{array}{c}3.80 \pm 0.79 \\
\text { (d) }\end{array}$ & $\begin{array}{c}0.62 \pm 0.05 \\
\text { (d) }\end{array}$ & $\begin{array}{c}0.10 \pm 0.01 \\
\text { (c) }\end{array}$ & $\begin{array}{c}2.10 \pm 0.18 \\
\text { (b) }\end{array}$ & $\begin{array}{c}8.00 \pm 0.90 \\
\text { (f) }\end{array}$ & ND & ND \\
\hline SA1 & $\begin{array}{c}27.00 \pm 2.40 \\
\text { (c) }\end{array}$ & $\begin{array}{c}11.10 \pm 0.10 \\
\text { (b) }\end{array}$ & $\begin{array}{c}14.43 \pm 1.20 \\
\text { (b) }\end{array}$ & $\begin{array}{c}1.01 \pm 0.10 \\
(\mathrm{ab})\end{array}$ & $\begin{array}{c}2.94 \pm 0.20 \\
\text { (a) }\end{array}$ & $\begin{array}{c}14.00 \pm 0.12 \\
\text { (c) }\end{array}$ & ND & ND \\
\hline SA2 & $\begin{array}{c}27.00 \pm 2.00 \\
\text { (c) }\end{array}$ & $\begin{array}{c}12.50 \pm 0.12 \\
\text { (a) }\end{array}$ & $\begin{array}{c}11.04 \pm 0.90 \\
\text { (c) }\end{array}$ & $\begin{array}{c}0.79 \pm 0.60 \\
\text { (b) }\end{array}$ & $\begin{array}{c}2.38 \pm 0.17 \\
\text { (b) }\end{array}$ & $\begin{array}{c}12.00 \pm 0.10 \\
\text { (d) }\end{array}$ & ND & ND \\
\hline $\mathrm{CAe}$ & $\begin{array}{c}25.00 \pm 1.90 \\
\text { (c) }\end{array}$ & $\begin{array}{c}4.00 \pm 0.32 \\
\text { (d) }\end{array}$ & $\begin{array}{c}16.19 \pm 1.40 \\
(\mathrm{ab})\end{array}$ & $\begin{array}{c}1.21 \pm 0.10 \\
(\mathrm{ab})\end{array}$ & $\begin{array}{c}1.80 \pm 0.09 \\
\text { (c) }\end{array}$ & $\begin{array}{c}15.00 \pm 0.13 \\
\text { (b) }\end{array}$ & ND & ND \\
\hline CA1 & $\begin{array}{c}44.00 \pm 3.00 \\
\text { (a) }\end{array}$ & $\begin{array}{c}8.10 \pm 0.90 \\
\text { (c) }\end{array}$ & $\begin{array}{c}16.21 \pm 1.40 \\
(\mathrm{ab})\end{array}$ & $\begin{array}{c}1.22 \pm 0.10 \\
(\mathrm{ab})\end{array}$ & $\begin{array}{c}2.10 \pm 0.16 \\
\text { (b) }\end{array}$ & $\begin{array}{c}16.00 \pm 0.14 \\
\text { (a) }\end{array}$ & ND & ND \\
\hline $\mathrm{CA} 2$ & $\begin{array}{c}31.00 \pm 2.79 \\
\text { (b) }\end{array}$ & $\begin{array}{c}8.80 \pm 0.10 \\
\text { (c) }\end{array}$ & $\begin{array}{c}17.00 \pm 1.50 \\
\text { (a) }\end{array}$ & $\begin{array}{c}1.42 \pm 0.20 \\
\text { (a) }\end{array}$ & $\begin{array}{c}2.15 \pm 0.18 \\
\text { (b) }\end{array}$ & $\begin{array}{c}15.80 \pm 0.12 \\
(\mathrm{ab})\end{array}$ & ND & ND \\
\hline
\end{tabular}

$n=6$; ${ }^{*}$ ND: non detected; Different letters in parenthesis indicate significant differences at $P \leq 0.05$ (LSD test); Experimental conditions as described in Sections 2.5 and 2.6; CC: control treatment, water potential was kept within the interval: $0.00-0.30 \mathrm{MPa}, \mathbf{S C}$ : water stress, water potential was kept within the interval: $-0.30-0.70 \mathrm{MPa}, \mathrm{CA1}$ : abscisic acid first year treatment, CA2: abscisic acid second year treatment, CAe: abscisic acid was supplied on a single date, SA1: combined treatment, water stress+abscisic acid first year treatment, SA2: combined treatment, water stress+abscisic acid second year treatment.

In agreement with other authors, postveraison ABA supply increased malvidin content [8, 16, 17], however it had no effect when applied at flowering. These results permitted to conclude that ABA does not trigger malvidin biosynthesis. Water stress combined with ABA presented the highest concentration, likely due to additive effects.

Catechin was not affected by water stress although ABA supply increased its concentrations about $1700 \%$. ABA treatments could affect the activity or gene expressions of LAR or/and BAN enzymes. The high concentrations of catechin stabilize the color of the wine and enhance its behavior during aging.

Quercetin response was similar than catechin, its concentration increased 800\% after ABA supply.

The ratio catechin/quercetin confirmed a higher activity or gene expressions of DFR, LAR or/and ANR than FLS1.

Malvidin/(catechin + quercetin) ratio indicates that water stress could be favoring the activity or gene expressions of LDOX and/or UFGT, in agreement with Castellarin et al. [6] results. The lower malvidin/(catechin + quercetin) ratio for $\mathrm{ABA}$ treatments could be explained taking into account that hormonal treatment significantly increased catechin and quercetin contents.

\section{Conclusions}

In this work, the individual determination of selected phenolic compounds after in-field combined treatments is presented and evaluated for the first time. The present approach offers the possibility of performing robust, sensitive, cost effective and versatile simultaneous evaluation of phenolic compounds in different samples of oenological interest during the whole winemaking and aging process.

We have demonstrated that it is possible to increase berry quality with ABA supply that simulates the signaling chain of water stress without the negative effects of this viticultural tool on vineyard yield. Indeed, the ability to increase the concentration of individual phenolic components in grape skin by the management of vine would provide interesting perspectives for enhancing wine quality.

Combined hormonal-water stress treatments produced three positive effects on wine quality; a) increments of blue compounds, b) increments of flavonols and flavan 3-oles that favor copigmentation of wines and c) higher antioxidant 
compounds concentration with the consequent health benefits.

The studies on ABA effects on the biosynthesis of secondary metabolites of great nutraceutical and industrial importance and should be extended to other varieties.

\section{Acknowledgments}

This work was supported by funding from Consejo Nacional de Investigaciones Científicas y Técnicas (CONICET), Agencia Nacional de Promoción Científica y Tecnológica (ANPCyT), and Secretaría de Ciencia, Técnica y Posgrado of Universidad Nacional de Cuyo (SECyTP-Project 06/A354).

\section{References}

[1] I.S. Pretorius and P.B. Hoj, Grape ad wine biotechnology: Challenges, opportunities and potential benefits, Aust J Grape Wine $R$ 11 (2005), 83

[2] M. Iriti and F. Faoro, Grape phytochemicals: a bouquet of old and new nutraceuticals for human health, Medical Hypothesis 67 (2006), 833.

[3] P. Ribéreau-Gayon, Y. Glories, A. Maujean and D. Dubourdieu, Phenolic Compounds. In: Handbook of Enology: The Chemistry of Wine and Stabilization and Treatments, John Wiley \& Sons, Chichester, England, (2006), Vol. 2, Chapter 6, p. 141.

[4] R. Corder, W. Mullen, N.Q. Khan, S.C. Marks, E.G. Wood and M.J. Carrier, et al., Oenology: Red wine procyanidins and vascular health, Nature 444 (2006), 566.

[5] J.M. Pezzuto, Resveratrol as an Inhibitor of Carcinogenesis, Pharm Biol 46 (2008), 443.

[6] S.D. Castellarin, A. Pfeiffer, P. Sivilotti, M. Degan, E. Peterlunger and G. Di Gaspero, Transcriptional Regulation of Anthocyanin Biosynthesis in Ripening Fruits of Grapevine under seasonal Water Deficit, Plant Cell and Environment 30 (2007), 1381.

[7] T. Yamane, S.T. Jeong, N. Goto-Yamamoto, Y. Koshita and S. Kobayashi, Effect of temperature on anthocyanin biosynthesis in grape berry skins, Am J Enol Viticult 57 (2006), 54.

[8] L. Deis, B. Cavagnaro, R. Bottini, R. Wuilloud and M.F. Silva, Water deficit and exogenous ABA significantly affect grape and wine phenolic composition under in field and in-vitro conditions, Plant Growth Regul (2011), in press.

[9] F. Berli, J. D’Angelo, B. Cavagnaro, R. Bottini, R. Willoud and M.F. Silva, Phenolic composition in grape berry skins Vitis vinifera 1, Cv. Malbec) ripened with different solar UV-B radiation levels by capillary zone electrophoresis, J Agr Food Chem 56 (2008), 2892.

[10] L. Taiz and E. Zieger, In: Plant Physiology, 2nd Edition (Sinauer Associates, Inc. Publishers, Sunderland, Massachusetts) (1998), pp. 725-757.

[11] R.C. Vallone, A. Nijensohn, B. Cavagnaro, E.E. Merlo, J.A. Maffei and H. Ojeda, Validation of a simple biological indicator of plant water status to determine irrigation timing of grapevines (Vitis Vinifera L.), Acta Horticulturae 646 (2004), 77.

[12] J. Leung and J. Giraudat, Abscicic acid signal transduction, Annu, Rev Plant Physiol Plant Mol Biol 49 (1998), 199.

[13] P.R. Dry, B.R. Loveys, M. Stoll, D. Stewart and M.G. McCarthy, Partial rootzone drying-an update, Aust J Grape Wine Res 438 (2000), 35.

[14] S. Zhang and W. Outlaw Jr, Abscicic acid introduced into the transpiration stream accumulates in the guard-cell apoplast and causes stomatal closure, Plant Cell Environment 24 (2001), 1045.

[15] P. Sansberro, L. Mroginski and R. Bottini, Foliar sprays with ABA promote growth of Ilex paraguariensis by alleviating diurnal water stress, Plant Growth Regul 42 (2004), 105.

[16] T. Ban, M. Ishimaru, S. Kobayashi, S. Shinozaki, N. Goto-Yamamoto and S. Horiuchi, Abscicic acid and 2,4-dichlorophenoxyaceic acid affect the expression of anthocyanin biosynthetic pathway genes in Kyoho grape berries, J Hortic Sci Biotech 78 (2003), 586.

[17] S.T. Jeong, N. Goto-Yamamoto, S. Kobayashi and M. Esaka, Effects of plant hormones and shading on the accumulation of anthocyanins and the expression of anthocyanin biosynthetic in grape berry skins, Plant Sci 167 (2004), 247.

[18] A.M. Quiroga, F. Berli, D. Moreno, B. Cavagnaro and R. Bottini, Abscisic acid sprays significantly increase yield per plant in vineyardgrown wine grape (Vitis vinifera L.) cv, Cabernet Sauvignon through increased berryset with no negative effects on anthocyanin content and total polyphenol index of both juice and wine, J Plant Growth Regul 28 (2009), 28.

[19] G. Hrazdina, G.F. Parsons and L.R. Mattick, Physiological and biochemical events during development and maturation of grape berries, Am J Enol Vitic 35 (1984), 220-227.

[20] P.K. Boss, C. Davies and S.P. Robinson, Analysis of the expression of anthocyanin pathway genes in developing Vitis vinifera L, cv Shiraz grape berries and the implications for pathway regulation, Plant Physiol 111 (1996), 1059-1066.

[21] F. Sparvoli, C. Martin, A. Scinza, G. Gavazzi and C. Tonelli, Cloning and molecular analysis of structural genes involved in flavonoid and stilbene biosynthesis in grape (Vitis Vinifera L.), Plant Mol Biol 24 (1994), 743-755. 
[22] J. Bogs, M.O. Downey, J.S. Harvey, A.R. Ashton, G.J. Tanner and S.P. Robinson, Proanthocyanidin synthesis and expression of genes encoding leucoanthocyanidin reductase and anthocyanidin reductase in developing grape berries and grapevine leaves, Plant Physiology 139 (2005), 652-663.

[23] J. Bogs, A. Ebadi, D. McDavid and S.P. Robinson, Identification of the flavonoid hydroxylases from grapevine and their regulation during fruit development, Plant Physiology 140 (2006), 279-291.

[24] C.J. Nakajima, R.W. Welford, M. Yamazaki, K. Saito and C.J. Schofield, Mechanistic studies on three 2-oxoglutarate-dependent oxygenases of flavonoid biosynthesis: Anthocyanidin synthase, flavonol synthase, and flavanone 3beta-hydroxylase, J Biol Chem 279(2) (2004), 1206-1216.

[25] K. Skogerson, M. Downey, M. Mazza and R. Boulton, Rapid Determination of Phenolic Components in Red Wines from UV-Visible Spectra and the Method of Partial Least Squares, Am J Enol Viticult 58 (2007), 318.

[26] V. Riou and C. Asselin, Potentiel polyphénolique disponible du raisin estimation rapide par extraction partielle a chaud, Le Progrès agricole et viticole 113 (1996), 382.

[27] J. Burns, W. Mullen, N. Landrault, L. Teissedre, M. Lean and A. Crozier, Variations in the profile and content of anthocyanins in wines made from Cabernet Sauvignon and hybrid grapes, J Agr Food Chem 50 (2002), 4096.

[28] M.J. Herderich and P.A. Smith, Analysis of grape and wine tannins: Methods, applications and challenges, Aust J Grape Wine Res 11 (2005), 205.

[29] R. Sáenz-López, P. Fernández-Zurbano and M.T. Tena, Analysis of aged red wine pigments by capillary zone electrophoresis, J Chromatogr A 1052 (2004), 191.

[30] A. Cifuentes, Recent advances in the application of capillary electromigration methods for food analysis, Electrophoresis 27 (2006), 283.

[31] P. Viñas, C. López-Erroz, J.J. Marín Hernández and M. Hernández-Córdoba, Determination of phenols in wines by liquid chromatography with photodiode array and fluorescence detection, J Chromatogr A 871 (2000), 85-93.

[32] E. Fan, K. Zhang, S. Jiang, C. Yan and Y. Bai, Analysis of trans-resvertarol in grapes by micro-high performance liquid chromatrography, Anal Sci 24 (2008), 1019.

[33] Z. Liang, B. Wu, P. Fan, C. Yang, W. Duan, X. Zheng, C. Liu and S. Li, Anthocyanin composition and content in grape berry skin in Vitis germplas, Food Chem 111 (2008), 837.

[34] M.I. Spranger, M.C. Climaco, B. Sun, N. Eiriz, C. Forunato, A. Nunez, M.C. Leandro, M.L. Avelar and A.P. Belchior, Differentiation of red winemaking technologies by phenolic and volatile composition, Anal Chim Acta 513 (2004), 151.

[35] L. Minuti, R.M. Pellegrino and I. Tesei, Simple extraction method and gas chromatography-mass spectrometry in the selective ion monitoring mode for the determination of phenols in wine, J Chromatogr A 1114 (2006), 263.

[36] L. Minuti and R. Pellegrino, Determination of phenolic compound in wines by novel matris solid-phase dispersion extraction and gas chromatography/mass spectrometry, J Chromatogr A 1185 (2008), 23.

[37] H. Ojeda, C. Andary, E. Kraeva, A. Carbonneau and A. Deloire, Influence of pre and post veraison water deficit on synthesis and concentration of skin phenolic compounds during berry growth of Vitis vinifera cv Shiraz, Am J Enol Viticult 53 (2002), 261.

[38] J.A. Kennedy, M.A. Mathews and A. Waterhouse, Effect of maturity and vine water status on grape skin and wine flavonoids, Am J Enol Viticult 53 (2002), 268.

[39] I.C. Dood and W.J. Davies, In Plant Hormones, Biosynthesis, Signal Transduction, Action!, Kluwer Academic Publishers, Dordrecht, Chapter E3, (2005), pp. 493-512.

[40] F. Jiang and W. Hartung, Long distance signaling of absisic acid (ABA): The factors regulating the intensity of the ABA signal, $J$ Exp Bot 59 (2008), 37.

[41] C. Van Leeuwen and G. Seguin, The concept of terroir in viticulture, J Wine Res 17 (2006), 1. 